\title{
Comparative Study of Nutritional Status of Children (02-24 Months) with Acute Bronchiolitis and Pneumonia
}

\author{
NN SHAMPA ${ }^{\mathrm{a}}, \mathrm{MAH}_{\mathrm{MOLLAH}}^{\mathrm{b}}, \mathrm{MM} \mathrm{BILL}^{\mathrm{c}}, \mathrm{ARML} \mathrm{KABIR}^{\mathrm{d}}, \mathrm{NC}^{\mathrm{S} A H A}{ }^{\mathrm{e}}$
}

\section{Summary:}

Background: Acute Bronchiolitis and pneumonia pose significant morbidity and mortality of under five children. This outcome is further influenced by poor nutritional status of the affected child because of depressed immunity.

Objective: We sought to evaluate nutritional status of children suffering from acute bronchiolitis and pneumonia in Bangladesh.

Methods: This cross sectional study was conducted in the Department of Pediatrics of Dhaka Medical College Hospital and Dhaka Shishu Hospital from July, 2010 to June, 2011. A total of 50 patients of pneumonia aged 2-24 months and 50 patients of acute bronchiolitis of same age were enrolled in this study according to case definitions. After enrolment, the patients were thoroughly assessed with particular emphasis on the anthropometric measurements. Weight, length, MUAC and $\mathrm{OFC}$ were measured and recorded in a pretested semi structured questionnaire. For each group $Z$ score of weight for age, weight for length, length for age, OFC and MUAC were calculated. $Z$ score +2 to -1 was defined as normal, -1 to -2 z score as mild poor, -2 to -3 z score as moderate poor and $<-3$ z score was defined as severe poor status. Results were

\section{Introduction:}

Acute respiratory tract infection (ARI) accounts for nearly one third of all under five deaths in Bangladesh ${ }^{1}$. Among them, pneumonia is the single largest contributor and accounts for almost $28-34 \%$ of all under five deaths globally ${ }^{2,3}$. Acute bronchiolitis, another common respiratory problem, is responsible for hospital admission

a. Dr. Nazmun Nahar Shampa, Assistant Professor, Harirampur Union Sub Center, Thana Health Complex, Tejgaon, Dhaka.

b. Prof. Md. Abid Hossain Mollah, Professor of Paediatrics \& Neonatology, Dhaka Medical College Hospital, Dhaka.

c. Dr. Mallick Masum Billah, OSD, Directorate General of Health Services, Mohakhali, Dhaka.

d. Prof. ARM Luthful Kabir, Professor of Paediatrics, Sir Salimullah medical College \& Mitford Hospital, Dhaka.।

e. Dr. Narayan Chandra Saha, Associate Professor of Paediatric Neurology, National Institute of Neuroscience and Hospital, Dhaka.

Address of Correspondence: Dr. Nazmun Nahar Shampa, Assistant Professor, Harirampur Union Sub Center, Thana Health Complex, Tejgaon, Dhaka. Mobile: 01715027955, E-mail: drnazmunnahar@yahoo.com

Received: 22 August 2015

Accepted: 9 Sept. 2016 compared between pneumonia group and bronchiolitis group by using calculated $Z$ value. $A$ calculated $Z$ value more than 1.96 was regarded significant (calculated $z$ value $>1.96$ is equivalent to $p$ value $<0.05$ ).

Results: Children with pneumonia more often had severe underweight (weight for age <-3 SD) (50\% vs. 30\%, $p=$ 0.04), microcephaly (OFC <-3SD) (30\% vs. 12\%, $p=0.03)$, and low MUAC $(<115 \mathrm{~mm})(40 \%$ vs. $10 \%, p=0.03)$ compared to those with bronchiolitis. Although, there was an increased trend of severe wasting (weight for length $<-3 S D$ ) and severe stunting (length for age $<-3$ SD) in children with pneumonia compared to those with bronchiolitis, the difference was not significant.

Conclusion: There thus, the overall nutritional status in children having pneumonia was poor compared to those with bronchiolitis. However, multicenter case control study with larger sample is imperative to consolidate our observation.

Key Words: Acute Bronchiolitis, pneumonia, Nutritional Status.

(J Bangladesh Coll Phys Surg 2017; 35: 9-14)

of $2-3 \%$ of all babies younger than one year of age $e^{1,4}$. Poor nutritional status leaves children susceptible to ARI and secondary infection because of impaired cellular immunity ${ }^{5}$. A recent systematic review revealed that death from pneumonia is as high as 15 folds with the co-morbidity of severe malnutrition compared to those without severe malnutrition ${ }^{6}$. Impact of severe malnutrition in children with bronchiolitis is also enormous ${ }^{7}$. However, in Bangladesh the studies evaluating the nutritional status of children suffering from pneumonia as well as bronchiolitis are limited. This study was designed to see the nutritional status of children suffering from pneumonia and bronchiolitis and to compare the results between the two groups. This understanding would encourage the improvement of nutritional status of children as a preventive measure against these two common respiratory problems.

Materials and Methods:

Study design , place and period: This observational cross sectional study was carried in Dhaka Medical 
College Hospital and Dhaka Shishu Hospital during July 2010 to June 2011.

Study population: The study was carried out among the 02-24 months old infants who were admitted in the selected hospitals with acute bronchiolitis and pneumonia.

\section{Case definitions:}

(A) Bronchiolitis: child below 2 years of age with fast breathing, wheeze, coryza and radiological evidence of bronchiolitis e.g hyperinflation of chest. (National ABC guideline, 2005, Asthma association, Bangladesh)

(B) Pneumonia: child below 2 years of age with cough, fast breathing, lower chest wall indrawing, fever, coarse crackles on auscultation and radiological evidence of pneumonia like consolidation or perihilar infiltrate (Pocket Book Of Hospital Care For Children: guideline for the management of common illness with limited resources: WHO 2005:71).

In both of the pneumonia and bronchiolitis groups' features of hypoxia like nasal flaring, grunting, head nodding were noted.

\section{Selection of cases:}

Inclusion criteria: Any child from two months to two years of age with meeting the case definition of pneumonia or bronchiolitis irrespective of sex and nutritional status were enrolled in the study.

Exclusion criteria: Patients having congenital heart diseases or other congenital anomalies, suffering from chronic illness like TB, thalassemia, malabsorption syndrome were excluded from the study.

Sample size and sampling: The samples are selected purposively based on the inclusion and exclusion criteria form Dhaka Medical College Hospital and Dhaka Shishu Hospital during July 2010 to June 2011. A total of 100 cases were selected initially in the pneumonia group. 45 of them were excluded because of having no radiological evidence of pneumonia and five were excluded because of having associated congenital heart diseases. 85 cases were selected in bronchiolitis group but 35 of them were excluded because of having no radiological evidence. Finally 50 patients were enrolled in each group.

Data collection: After enrolment, thorough clinical assessment was done using a pretested semi structured questionnaire. As a part of anthropometric measures weight, length, Occipito Frontal Circumference (OFC) and Mid Upper Arm Circumference (MUAC) were noted. Naked weight was measured using an electronic scale that stands a maximum weight $15 \mathrm{Kg}$ with $100 \mathrm{gm}$ precision. The measurement of length was done in infantometer from the top of the head to the heels with the child lying on a wood slab with a fixed piece on one side and a movable one on the other side (top of the head on the fixed part). MUAC and OFC were measured by a measuring tape with a precision of $1 \mathrm{~mm}$. MUAC was measured among children of more than 6 months of age. We measured weight in Kilogram, Length and OFC in Centimeter and MUAC in Millimeter.

Classification of nutritional status: To assess the nutritional status z scores of weight for age, weight for length, length for age, MUAC and OFC were calculated. Normal range was defined as +2 to $-1 \mathrm{z}$ scores, mild poor status as -1 to $-2 z$ scores, moderate poor status as -2 to $-3 \mathrm{z}$ scores and severe poor status as $<-3 \mathrm{z}$ score ${ }^{8,9}$.

Statistical analysis: Calculated $Z$ values were determined for each group for comparison between pneumonia and bronchiolitis cases. $Z$ values $>1.96$ were considered as significant $(Z$ values $>1.96$ equivalent to $p<0.05)$.

Ethical consideration: The ethics and research committee of Dhaka Medical College Hospital approved the study and was carried out.

\section{Results:}

In this study, among the data of 100 cases (50 in pneumonia and 50 in bronchiolitis group) male outnumbered female (58\% in pneumonia and $68 \%$ in bronchiolitis groups). Children of 2-6 months age group were predominant (Table I). Fever, cough, respiratory distress and chest indrawing were present in $100 \%$ patients of pneumonia group. On the other hand, respiratory distress and wheeze were present in 100\% patients of bronchiolitis group. Features of hypoxia like flaring of ala nasae, head nodding, grunting and cyanosis were more frequent among the children of pneumonia group than their bronchiolitis counterparts (Table II). Among the pneumonia cases, perihilar infiltrate on the chest $x$ ray was the predominant finding ( $42 \%$ ) followed by lobar consolidation (36\%) and bilateral patchy opacity (22\%). On the other hand hyperinflation (46\%) was predominant among the bronchiolitis cases followed by both hyperlucency and hyperinflation (22\%) (Table III). Children with microcephaly (OFC $<-$ $3 \mathrm{SD}$ ), severe underweight (weight for age $<-3 \mathrm{SD}$ ), and MUAC $<115$ were significantly more in pneumonia cases than their bronchiolitis counterparts (Table IV). Number of mild to severely wasted and stunted children were also more in pneumonia group than their bronchiolitis counterparts, though the differences were not statistically significant (Table IV). 


\section{Table-I}

Age and sex distribution of pneumonia and bronchiolitis patients

\begin{tabular}{llcc}
$\begin{array}{l}\text { Characteristics } \\
\text { Age (in months) }\end{array}$ & $\begin{array}{c}\text { Pneumonia } \\
\mathrm{n}=50\end{array}$ & $\begin{array}{c}\text { Bronchiolitis } \\
\mathrm{n}=50\end{array}$ \\
\hline \multirow{2}{*}{$\begin{array}{l}\text { Sex } \\
\text { Se }\end{array}$} & $25(50 \%)$ & $31(62 \%)$ \\
& $6-12$ & $14(28 \%)$ & $14(28 \%)$ \\
& $12-24$ & $11(22 \%)$ & $5(10 \%)$ \\
& & & $34(68 \%)$ \\
& Male & $29(58 \%)$ & $16(32 \%)$ \\
\hline
\end{tabular}

\section{Table-II}

Clinical features of pneumonia and bronchiolitis patients.

\begin{tabular}{lcc} 
Clinical features & Pneumonian $=50(\%)$ & Bronchiolitisn=50 $(\%)$ \\
\hline Fever & $50(100)$ & $32(64)$ \\
Cough & $50(100)$ & $42(84)$ \\
Respiratory distress & $50(100)$ & $50(100)$ \\
Chest indrawing & $50(100)$ & $35(70)$ \\
Wheeze & $10(20)$ & $50(100)$ \\
Flaring of ala nasae & $20(40)$ & $12(24)$ \\
Head nodding & $13(26)$ & $03(06)$ \\
Grunting & $08(16)$ & $05(10)$ \\
Cyanosis & $06(12)$ & $02(04)$ \\
\hline
\end{tabular}

\section{Table-III}

Radiological features of pneumonia and bronchiolitis patients

\begin{tabular}{llc} 
Group of patients & Radiological features & No. of patients $(\%)$ \\
\hline Pneumonia & Perihilar infiltrate & $21(42 \%)$ \\
& Bilateral patchy opacity & $11(22 \%)$ \\
& Lobar consolidation & $18(36 \%)$ \\
Bronchiolitis & Hyperinflation & $23(46 \%)$ \\
& Hyperlucency & $9(18 \%)$ \\
& Both hyperlucency and hyperinflation & $11(22 \%)$ \\
& Hyperinflation and streaky density & $6(12 \%)$ \\
\hline
\end{tabular}


Table-IV

\begin{tabular}{lccccc}
\multicolumn{5}{c}{ Comparison of anthropometric measures of Pneumonia and Bronchiolitis patients } \\
Anthropometry & Standard & Pneumonia & Bronchiolitis & Calculated & $\mathrm{p}$ \\
& Deviation & $\mathrm{n}(\%)$ & $\mathrm{n}(\%)$ & Z value & \\
\hline Occipito Frontal Circumference & +2 to -1 & $06(12 \%)$ & $06(12 \%)$ & 0 & 1.00 \\
& -1 to -2 & $15(30 \%)$ & $23(46 \%)$ & 1.67 & 0.09 \\
& -2 to -3 & $14(28 \%)$ & $15(30 \%)$ & 0.22 & 0.08 \\
& $<-3$ & $15(30 \% 0)$ & $06(12 \%)$ & 2.26 & 0.03 \\
Weight/Age(under nutrition) & +2 to -1 & $06(12 \%)$ & $09(18 \%)$ & 0.843 & 0.4 \\
& -1 to -2 & $09(18 \%)$ & $12(24 \%)$ & 0.73 & 0.4 \\
& -2 to -3 & $10(20 \%)$ & $14(28 \%)$ & 0.94 & 0.3 \\
Weight/Length & $<-3$ & $25(50 \%)$ & $15(30 \%)$ & 2.08 & 0.04 \\
& +2 to -1 & $08(16 \%$ & $16(32 \%)$ & 1.9 & 0.06 \\
& -1 to -2 & $12(24 \%)$ & $16(32 \%)$ & 0.89 & 0.4 \\
& -2 to -3 & $15(30 \%)$ & $10(20 \%)$ & 1.25 & 0.2 \\
Mid upper arm circumference & $<-3$ & $15(30 \%)$ & $08(16 \%)$ & 1.68 & 0.09 \\
& $\geq 115$ & $15(60 \%)$ & $17(89.8 \%)$ & 4.14 & 0.03 \\
& $<115$ & $10(40 \%)$ & $02(10.2 \%)$ & 4.14 & 0.03 \\
& & & & \\
Length/Age(stunting) & +2 to -1 & $08(16 \%)$ & $12(24 \%)$ & 1.005 & 0,3 \\
& -1 to -2 & $20(40 \%)$ & $24(48 \%)$ & 0.8 & 0.4 \\
& -2 to -3 & $12(24 \%)$ & $06(12 \%)$ & 1.5 & 0.1 \\
& $<-3$ & $10(20 \%)$ & $08(16 \%)$ & 0.52 & 0.6 \\
\hline
\end{tabular}

\section{Discussion:}

The most important observation of this study is the frequent association of microcephaly (OFC $<-3 \mathrm{SD}$ ), severe underweight (weight for age $<-3 \mathrm{SD}$ ), and MUAC $<115$ with children having pneumonia compared to the children with bronchiolitis. Although, children with pneumonia proportionately more likely to be wasted and stunted compared to those with bronchiolitis, the difference was not significant and this might be due to small sample.

Common age group of pneumonia and bronchiolitis cases were 2-6 month of age. Several studies showed same findings that the younger age group is more vulnerable to lower respiratory tract infection ${ }^{10,11}$. There is a male predominance in both pneumonia (58\%) and bronchiolitis (68\%) groups. ARI as a whole affects males more frequently than females throughout the world ${ }^{12,13}$. This may be due to genetic factors or cultural practice of seeking medical care frequently for males than females, considering males more precious ${ }^{14,15}$.
It is known that poor nutrition is one of the causes of microcephaly ${ }^{16}$. In this study under nutrition and wasting is more prevalent in pneumonia group and consistently microcephaly is also significantly more in pneumonia group in comparison to bronchiolitis group $(\mathrm{p}<0.05)$.

In a study conducted in Bangladesh to investigate the host risk factors in the outcome of severe pneumonia, the findings were consistent. Similar type of another study conducted on ARI in Bangladesh also had consistent observation ${ }^{17}$. On the other hand, one study on nutritional status of bronchiolitis patient showed that only $7.5 \%$ had severe under nutrition, $72 \%$ had good nutritional status ${ }^{18}$. And these are almost consistent with the observation of our study population with bronchiolitis.

A number of previous studies were conducted to evaluate the nutritional status of children with pneumonia and bronchiolitis. Most of those studies assessed only one or two components of nutritional 
anthropometry. But our study is unique in the context of assessing most of the components of nutritional anthropometry (such as weight for age, weight for length, length for age, OFC and MUAC) of children having pneumonia and bronchiolitis patients of same demographic characteristics. Thus, on the basis of all the evaluated parameters our main observation was that the children with pneumonia more often had poor nutritional status compared to the children having bronchiolitis. The observation is understandable but very important. Children with poor nutritional status are immune-compromised due to depressed cell mediated and humoral immune responses and often more susceptible to severe bacterial infection ${ }^{19}$. Bacterial infection in children more likely to be associated with pneumonia compared to bronchiolitis ${ }^{20}$. Moreover, children with poor nutritional status more likely to be associated with bacterial pneumonia ${ }^{21,22}$. This explains our observation of association of pneumonia with poor nutritional status compared to bronchiolitis.

There were limitations in the study. The study was performed over small sample of children and selected the samples purposively. The selection bias could not be ruled out. But the study included all the children meeting the case definition and inclusion and exclusion criteria. As it was a cross sectional study, the findings did not determine the temporal relationship between the nutritional status and pneumonia and bronchiolitis.

\section{Conclusion:}

In conclusion, the results of our data suggest that children with low MUAC, severe under nutrition and microcephaly were more prone to have pneumonia compared to bronchiolitis. Overall nutritional status was poor in pneumonia cases in comparison to bronchiolitis cases.

\section{Recommendation:}

Multicenter case control study with large sample size may be conducted to determine more precise relationship between the nutritional status and pneumonia and bronchiolitis.

\section{References:}

1. Kabir ARML, Amin MR, Mollah MAH, Khanam S, Mridha AA, Ahmed S, Rokonuddin K, Chisti MJ. Respiratory disorders in under-five children attending different hospitals of Bangladesh: a cross sectional survey. Journal of Respiratory Medicine Research and Treatment 2015; [in press]
2. UNICEF. (2014). Committing to Child Survival: A Promise Renewed. Progress Report 2014.

3. Wardlaw T, Salama P, Johansson EW, et al. Pneumonia the leading killer of children. The Lancet 2006; 368 : 1048-50.

4. Smyth RI, Peter JM. Bronchiolitis. The Lancet 2006;368:312-322.

5. Ahmed T, Ali M, Ullah MM, Choudhury IA, Haque ME, Salam MA, Rabbani GH, Suskind RM \& Fuchs GJ. Mortality in severely malnourished children with diarrhoea and use of a standardised management protocol. The Lancet 1999;353:1919-22.

6. Chisti MJ, Tebruegge M, La Vincente S, Graham SM \& Duke T. Pneumonia in severely malnourished children in developing countries - mortality risk, aetiology and validity of WHO clinical signs: a systematic review. Trop Med Int Health 2009;14:1173-89.

7. Bosa VL, Mello ED, Mocelin HT, Benedetti FJ, Fischer GB. Assessment of nutritional status in children and adolescents with post-infectious bronchiolitis obliterans. J Pediatr (Rio J) 2008;84(4):323-30.

8. WHO Expert Committee on Physical Status: the Use and Interpretation of Anthropometry: report of a WHO expert committee. WHO technical report series: 854, 1995.

9. World Health Organization. Management of Severe Malnutrition: a manual for physicians and other senior health workers. Geneva,1999.

10. Rijal P, Sharma A, Shrestha S and Upadhyay S. Profile of acute lower respiratory tract infection in children under fourteen years of age at Nepal Medical College Teaching Hospital (NMCTH). Nepal Med Coll Journal 2011; 13(1):58-61.

11. Simoes EA. Respiratory syncytial virus infection. Lancet 1999;354:847-52.

12. Kwon JM, Shim JW, Kim DS et al. Prevalence of respiratory viral infection in children hospitalized for acute lower respiratory tract diseases, and association of rhinovirus and influenza virus with asthma exacerbations. Korean J Pediatr 2014;57(1):29-34.

13. Victoria CG, Fuchs SC, Flores JAC, Fonseca W, Kirkwood B. Risk factors for pneumonia among children in a Brazilian metropolitan area. Pediatrics 1994; 93(6): 977-86.

14. Suwanjutha S, Ruangkanchanasetr S, Chantarojanosiri T, Hotrakitya S. Risk factors for pneumonia in Thai children under 5 years. Southeast Asian J Trop Public Health 1994;25(1):60-5.

15. Khanam R. Risk factors for acute respiratory infections (ARI) in children (dissertation). Dhaka. Bangladesh College of physicians and Surgeons, 1994. 
16. Kabir ARML, Mollah AH, Anwar KS, Rahman AKMF, Amin R, Rahman ME. Management of bronchiolitis without antibiotics: a multi-center randomized control trial in Bangladesh. Acta Pediatrica 2009;98:1593-1599.

17. Paul SK, Sharma JD et al. Host risk factors in the outcome of severe pneumonia. D S (Child) H J. 2006;22(1):23-28.

18. Berman S. Epidemiology of acute respiratory infections in children of developing countries. Rev Infec Dis 1992;13(6):54-62.

19. Morgan G. What, if any, is the effect of malnutrition on immunological competence? The Lancet 1997;349: $1693-1695$.

20. Adiku TK, Asmah RH, Rodrigues O, Goka B, Obodai E, Adjei AA, Donkor ES, Armah G. Aetiology of acute lower respiratory infections among children under five years in Accra, Ghana. Pathogens. 2015;4:22-33

21. Chisti MJ, Graham SM, Duke T, Ahmed T, Ashraf H, Faruque AS, La Vincente S, Banu S, Raqib R \& Salam MA. A Prospective Study of the Prevalence of Tuberculosis and Bacteraemia in Bangladeshi Children with Severe Malnutrition and Pneumonia Including an Evaluation of Xpert MTB/RIF Assay. PLoS One, 2014 9, e93776.

22. Chisti MJ, Ahmed T, Faruque AS \& Salam AM. Clinical and laboratory features of radiologic pneumonia in severely malnourished infants attending an urban diarrhea treatment center in Bangladesh. Pediatr Infect Dis J 2010;29:174-7. 